\title{
Perspective
}

\section{Designing Pt-based Electrocatalysts with High Surface Energy}

\author{
Tian Sheng, Na Tian, Zhi-You Zhou, Wen-Feng Lin, and Shi-Gang Sun
}

ACS Energy Lett., Just Accepted Manuscript • DOI: 10.1021/acsenergylett.7b00385 • Publication Date (Web): 26 Jul 2017

Downloaded from http://pubs.acs.org on July 27, 2017

\section{Just Accepted}

"Just Accepted" manuscripts have been peer-reviewed and accepted for publication. They are posted online prior to technical editing, formatting for publication and author proofing. The American Chemical Society provides "Just Accepted" as a free service to the research community to expedite the dissemination of scientific material as soon as possible after acceptance. "Just Accepted" manuscripts appear in full in PDF format accompanied by an HTML abstract. "Just Accepted" manuscripts have been fully peer reviewed, but should not be considered the official version of record. They are accessible to all readers and citable by the Digital Object Identifier (DOI®). "Just Accepted" is an optional service offered to authors. Therefore, the "Just Accepted" Web site may not include all articles that will be published in the journal. After a manuscript is technically edited and formatted, it will be removed from the "Just Accepted" Web site and published as an ASAP article. Note that technical editing may introduce minor changes to the manuscript text and/or graphics which could affect content, and all legal disclaimers and ethical guidelines that apply to the journal pertain. ACS cannot be held responsible for errors or consequences arising from the use of information contained in these "Just Accepted" manuscripts. 


\title{
Designing Pt-based Electrocatalysts with High Surface Energy
}

\author{
Tian Sheng ${ }^{\mathrm{a}}$, Na Tian ${ }^{\mathrm{a}}$, Zhi-You Zhou ${ }^{\mathrm{a}}$, Wen-Feng Lin ${ }^{\mathrm{b}}$, Shi-Gang Sun ${ }^{\mathrm{a}, *}$ \\ ${ }^{\text {a }}$ State Key Laboratory of Physical Chemistry of Solid Surfaces, Collaborative \\ Innovation Center of Chemistry for Energy Materials, College of Chemistry and \\ Chemical Engineering, Xiamen University, Xiamen, 361005, P. R. China. \\ ${ }^{\mathrm{b}}$ Department of Chemical Engineering, Loughborough University, Loughborough, \\ Leicestershire, LE11 3TU, U.K. \\ *corresponding author: sgsun@xmu.edu.cn
}

\begin{abstract}
The reactivity of an electrocatalyst depends strongly on its surface structure. Pt-based electrocatalysts of nanocrystals (NCs) enclosed with high-index facets contain a large density of catalytically active sites formed from step and kink atoms on the facets, and exhibit intrinsically superior activity. However, the Pt-based NCs of high-index facets do possess a high surface energy and are thermodynamically metastable, leading to a big challenge in their shape-controlled synthesis. To overcome the challenge, kinetic/thermodynamic control of crystal growth is indispensable, and is currently realized mainly by electrochemical method and surfactant-based wet chemical approach. This article reviews recent progresses in Pt-based electrocatalysts of monometallic and bimetallic NCs of high surface energy with different morphologies of convex or concave tetrahexahedron (THH), trapezohedron $(\mathrm{TPH})$, trisoctahedron $(\mathrm{TOH})$, hexoctahedron $(\mathrm{HOH})$, etc. Remarkable electrocatalytic performance of these NCs has been demonstrated. Despite the considerable progresses already been made, the electrocatalysts of NCs with high surface energy still hold significant future opportunities in both fundamental
\end{abstract}


understanding and practical applications.

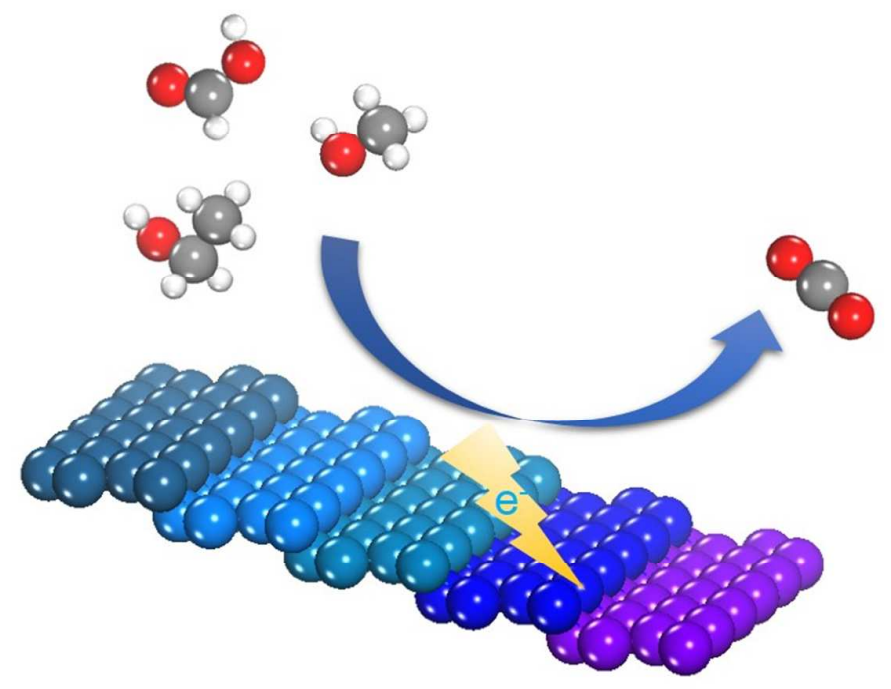

Fuel cells convert directly the chemical energy of externally supplied fuel and oxidant into electrical energy with high efficiency, and are a promising clean energy solution to solve the pollution and low efficiency of traditional fossil fuel technologies. Pt-based electrocatalysts play a vital role in the fuel cell reactions, where they commonly consist of nanoparticles well dispersed on conductive materials. ${ }^{1}$ Electrocatalytic reactions occur on the catalyst surface. To enhance the catalytic performance, the surface area of the catalysts should be as large as possible by decreasing the particle size. However, this approach will be limited by poor stability of too small-size nanoparticles (e.g., $<3 \mathrm{~nm}$ ). Engineering surface structure of the catalysts becomes an alternative approach that can further boost the catalytic properties effectively. The catalytic active sites are usually composed of a few low-coordinated atoms on steps, edges and kinks. ${ }^{2-4}$ As for face-centered-cubic Pt-group metals, high Miller index facets, $\{h k l\}$ with one of values bigger than one, contain high density of atomic steps, therefore possess a much higher reactivity than low-index facets on which atoms are compactly arranged and smooth. In fact, the larger number of low-coordinated sites on a catalyst surface, the higher surface energy and higher activity it will possses. ${ }^{5-9}$

Under thermodynamic growth conditions, nanocrystal (NC) growth is generally 
governed by the order of surface energy, giving rise to the rapid disappearance of high energy surface. The final NCs are usually enclosed by low energy surfaces, such as $\{111\}$ and $\{100\}$ facets. Thus, the preparation of NCs with high surface energy presents a huge challenge in the field of shape-controlled synthesis. ${ }^{5-9}$ Nevertheless, NCs with high surface energy can provide a promising platform to fundamentally understand the principles in surface science and heterogeneous catalysis, such as the surface structure-catalytic property relationship at nanoscales, the latter is the key to shed light on the rational design of practical catalysts with high activity and durability for energy conversion devices such as fuel cells.

In current fuel cell technologies, platinum is the key catalyst for both anode (hydrogen oxidation, methanol oxidation, etc.) and cathode (oxygen reduction) reactions. The surface structure of Pt NCs can be readily illustrated by a stereographic projection triangle (Figure 1)..$^{5}$ The coordination numbers of outmost layer of polyhedra located at the three triangle vertexes are 9,8 and 7, corresponding to the $\{111\},\{100\}$, and $\{110\}$ facets, respectively, with the order in surface energy of $\{111\}$ $<\{100\}<\{110\}$. The polyhedra lying on the three sidelines or inside of the triangle are enclosed by, i.e., $\{h k 0\},\{h k k\},\{h h l\}$ and $\{h k l\}(h>k>l \geq 1)$, with the coordination number of surface atoms being generally equal to or smaller than 7 , and the corresponding single forms are tetrahexahedron (THH), trapezohedron (TPH), trisoctahedron $(\mathrm{TOH})$ and hexoctahedron $(\mathrm{HOH})$. High-index facets possess high density of low-coordinated step/kink atoms, therefore having high surface energy.

Two wet-chemical approaches, wet-chemical route based on surfactants and electrochemical method, are usually employed for shape-controlled synthesis of Pt-group metal NCs with high surface energy. In the surfactant-based chemical synthesis strategies, the surfactants or capping agents (such as PVP, CTAB, and halide ions) play a key role in tuning growth kinetics through covering specific $\mathrm{NC}$ facets. ${ }^{7-9}$ Capping agents can preferentially adsorb on the low coordinated atoms, and stabilize them, resulting in the change of the order of surface energy mentioned above. The growth rate towards high-energy surface direction is slowed down and thus high-energy facets are preserved on the final synthesized NCs. ${ }^{7-9}$ Unfortunately, these 
capping agents can significantly influence the catalytic performance of the NCs. Usually, a tedious washing routine is needed to remove the capping agents. By contrast, the electrochemical route is powerful to synthesize NCs with clean facets. In early studies, electrochemical methods have been reported to reshape the bulk Pt electrode or to grow faceted Pt crystallites with preferential crystallographic orientations. ${ }^{10}$ Both the nucleation and growth of metal NCs can be controlled through adjusting electrode potential, current or other parameters. ${ }^{11-14}$ In the past decades, our group has developed an electrochemical square-wave potential (SWP) method to synthesize Pt-group metal NCs with high surface energy. ${ }^{11-14}$ The nucleation, growth and oxidative etching can be readily controlled by this SWP approach. The formation mechanism of Pt high-index facets is as following: ${ }^{11}$ At the lower potential limit $\left(E_{\mathrm{L}}\right)$ of the SWP, the Pt precursor ions in solution are reduced and deposited onto the electrode surface. At the upper potential limit $\left(E_{\mathrm{U}}\right)$, oxygen species (such as $\mathrm{OH}$ and $\mathrm{O}$ ) derived from $\mathrm{H}_{2} \mathrm{O}$ dissociation can adsorb on the Pt surfaces. Some of oxygen species will invade into Pt surface through place-exchange between Pt atoms and oxygen atoms. As a result, some Pt atoms are squeezed out. When the potential turns back to the $E_{\mathrm{L}}$, the oxygen species reductively desorb, but the displaced Pt atoms cannot always return to their original positions, leading to the formation of step or kink sites. The repetitive oxygen adsorption/desorption mediated by the SWP can reconstruct the surface and finally induce the formation of high-index facets with high density of step atoms.

By the SWP method, THH Pt NCs with $\{730\}$ facets were synthesized (Figure 2a), presenting high catalytic activity towards both ethanol and formic acid electrooxidation. ${ }^{11}$ The electrooxidation of small organic molecules involves the cleavage of strong $\mathrm{C}-\mathrm{H}$ bond which usually serves as the rate-determining step (RDS). The low-coordinated step atoms on high-index facets can strongly interact with reactants, and promote the cleavage of $\mathrm{C}-\mathrm{H}$ bond, thus showing high activity commonly. THH Pt NCs exhibit a catalytic activity of 2.0 3.1 times higher than commercial $\mathrm{Pt} / \mathrm{C}$ catalysts for formic acid oxidation, and 2.5 4.6 times higher for ethanol oxidation (Figure 2b). Moreover, in spite of the high surface energy, THH Pt 
NCs are stable thermally at $800{ }^{\circ} \mathrm{C} .^{11}$

The SWP method is a universal approach for the synthesis of Pt-group metal (e.g., $\mathrm{Pt},{ }^{11} \mathrm{Pd},{ }^{12}$ and $\mathrm{Rh}^{13}$ ) NCs with high-index facets. By systematically altering the electrodeposition conditions, such as, precursor concentration, electrolyte, $E_{\mathrm{L}}, E_{\mathrm{U}}$ and frequency of SWP, a series of high-index faceted Pt NCs have been prepared, including THH NCs with $\{730\},\{310\}$, and $\{210\}$ facets, ${ }^{11,14-17}$ TPH NCs with $\{522\}$ facets, ${ }^{18}$ convex or concave HOH Pt NCs enclosed by $\left\{\begin{array}{lll}15 & 5 & 3\end{array}\right\}$ and $\left\{\begin{array}{ll}321 \\ \text { f facets, }\end{array}{ }^{13,19}\right.$ triambic icosahedral (TIH) Pt NCs with $\{771\}$ facets $^{20}$ and concave THH Pt NCs with $\{910\}$ facets $^{21}$ (Figure 2c and 2d). The above Pt NCs exhibit high catalytic activity (Table 1), around 3 5 times higher than that of commercial $\mathrm{Pt} / \mathrm{C}$ catalysts towards electrooxidation of formic acid and ethanol.

In wet-chemical routes, some Pt NCs with high-index facets were also synthesized. $^{22-24}$ The uniform four-armed star-like concave Pt NCs having $\{411\}$ facets, as shown in Figure 2e, were synthesized using methylamine as capping agents. The $\{411\}$ faceted Pt NCs exhibit an activity of 5.6 times higher than Pt/C for formic acid electrooxidation, and 6.0 times higher than $\mathrm{Pt} / \mathrm{C}$ for ethanol electrooxidation (Figure 2f $){ }^{22}$ Also, the concave THH Pt NCs with $\{510\},\{720\}$ and $\{830\}$ facets were synthesized by reduction of $\mathrm{K}_{2} \mathrm{PtCl}_{4}$ with $\mathrm{NaBH}_{4}$ in the presence of $\mathrm{Na}_{2} \mathrm{H}_{2} \mathrm{P}_{2} \mathrm{O}_{7}$ and $\mathrm{KBr}^{23}$ In this case, a Pt pyrophosphato complex generated from $\mathrm{PtCl}_{4}{ }^{2-}$ and $\mathrm{H}_{2} \mathrm{P}_{2} \mathrm{O}_{7}{ }^{2-}$ plays a key in the formation of such a concave shape, and at the meantime $\mathrm{Br}^{-}$can protect the $\{100\}$ facets as a capping agent. Zhang et al. reported a high-yield synthesis of multipod Pt NCs with $\{211\}$ and concave Pt NCs with $\{411\}$ facets from $\operatorname{Pt}(\square)$ acetylacetonate via a solvothermal method, by using 1-octylamine as the solvent and capping agent, and formaldehyde as a shape regulator. ${ }^{24}$ They found that concave Pt NCs with $\{411\}$ facets formed in the presence of formaldehyde while multipod Pt NCs with $\{211\}$ facets in the absence of formaldehyde. The underlying reason was deduced that amine can effectively stabilize the monoatomic step edges resulting in the exposed $\{211\}$ facets, and the decomposition of formaldehyde into carbon monoxide results in the exposed $\{411\}$ facets. We note that most of high-index faceted Pt NCs synthesized by surfactant-assistant wet chemical methods 
are concave shapes, ${ }^{9}$ while those synthesized by electrochemical method are convex. ${ }^{11-14}$ The exact reason still needs further investigation. Moreover, metal NCs with high-index facets contain various surface sites, such as step and terrace sites on the facets, as well as crystal edges. Currently, only overall catalytic activity can be measured yet. It is significant to develop high spatial resolved spectroscopic or probing technologies to evaluate the catalytic functions of the different surface sites.

All catalytic activity mentioned above is evaluated by current density $\left(j_{s}\right)$, that is, the electrooxidation current is normalized by electrochemical surface area (ECSA) of Pt. The current density characterizes the intrinsic activity which is equivalent to turnover frequency (TOF) in heterogeneous catalysis. Area-specific activity is commonly used in fundamental studies. From the viewpoint of practical applications, the mass specific activity $\left(j_{\mathrm{m}}\right)$ is more important, which also reflects the Pt utilization. The $j_{s}$ and $j_{m}$ hold the relationship of $j_{\mathrm{m}}=j_{\mathrm{s}} \times A_{\mathrm{s}}$, where $A_{\mathrm{s}}$ is specific ECSA per gram of Pt. The above displayed Pt NCs with high surface energy are of relatively large sizes $(>20 \mathrm{~nm})$, thus having a low $A_{\mathrm{s}}$ or Pt utilization. As for practical applications, a challenge is how to synthesize small-sized $(<10 \mathrm{~nm})$ Pt NCs with high surface energy. Two approaches were developed to this purpose: (1) Choosing the suitable precursors. Zhou et al. employed insoluble $\mathrm{Cs}_{2} \mathrm{PtCl}_{6}$ particles dispersed on carbon black as precursors and obtained high-index faceted Pt (HIF-Pt) NCs with a small size of 2-10 $\mathrm{nm}$ by applying SWP treatment. ${ }^{17}$ Aberration-corrected high-resolution transmission electron microscopy (HRTEM) shows that the HIF-Pt NCs have high density of step atoms, ${ }^{17}$ which promote the splitting the $\mathrm{C}-\mathrm{C}$ bond in ethanol electrooxidation. ${ }^{25,26}$ However, the shape of HIF-Pt prepared by this method is not very perfect. (2) Shape transformation from Pt crystal seeds by the SWP method. For example, the 10 nm-sized Pt nanocubes with $\{100\}$ facets can be converted into perfect $13 \mathrm{~nm}$-sized THH Pt NCs enclosed by $\{310\}$ facets by the SWP treatment in $0.1 \mathrm{M} \mathrm{H}_{2} \mathrm{SO}_{4}$ solution (Figure 3a). ${ }^{15}$ The surface structure, characterized by cyclic voltammograms is well consistent with the shape transformation: Hydrogen adsorption on two-dimensional (2D) (100)-domain sites disappears completely, while that on 1D (100)-domain site changes little. Meanwhile, the hydrogen adsorption on (110) steps increases greatly 
(Figure 3b). Likewise, by treating small Pt particles of $\sim 3 \mathrm{~nm}$ supported on graphene using $\operatorname{SWP}\left(E_{\mathrm{L}}=-0.30 \mathrm{~V}, E_{\mathrm{U}}=1.15 \mathrm{~V}\right.$, and $\left.f=10 \mathrm{~Hz}\right)$, sub-10 nm THH Pt NCs with $\{210\}$ high-index facets were obtained (Figure 3c). ${ }^{16}$ This method can even be extended to reshape commercial $\mathrm{Pt} / \mathrm{C}$ catalyst and to create high-index facets also (denoted as Pt/C_SWP), as shown in Figure 3d. Although the particle size increases from 3.1 to $6.3 \mathrm{~nm}$ after the SWP treatment, the loss in the ECSA can be compensated by the gain in area-specific activity: The area-specific activity of Pt/C_SWP is 0.83 $\mathrm{mA} \mathrm{cm}{ }^{-2}$, about 2.7 times higher than that of pristine $\mathrm{Pt} / \mathrm{C}$ catalyst for ethanol electrooxidation. As a result, the mass activity increases by 53\% (Figure 3e). High-index facets on Pt NCs can survive after harsh electrochemical oxidation/reduction, wherefore they possess high electrochemical stability. In addition, relatively large size also benefits the stability. After 1000 potential cycles between -0.26 and 1.10 V (vs SCE), only $28 \%$ activity was decayed for Pt/C_SWP. In contrast, the pristine $\mathrm{Pt} / \mathrm{C}$ catalysts lost the $51 \%$ of initial activity (Figure 3f). On the other hand, the synthesis of very large (a few to tens of micrometers) Pt-group metal NCs is also interesting. Such an individual crystal may serve as a new microelectrode with well-defined surface structure. Currently, the largest size of Pt NCs with high-index facets is about $2 \mu \mathrm{m} .^{14}$

Pure Pt catalysts, however, are not efficient for direct alcohol fuel cells because of the rapid poisoning of surface by the strongly adsorbed species, i.e., $\mathrm{CO}$ adsorbates, derived from the dissociative adsorption of organic molecules. ${ }^{27-29}$ Thus, substantial efforts have been made to mitigate the poisoning by introduction of a second element to $\mathrm{Pt}^{30-35}$ Bimetallic NCs usually show higher catalytic activity than the pure metal NCs as the adding element can change the steric and electronic structures (ligand and strain effects) and thus tune the binding energy of intermediates, or can provide bifunctional effects for catalysis. ${ }^{30-32,36}$ For improving the catalytic performance, how to obtain the NCs with desirable surface structures and element distributions is a formidable task. According to the element distribution, bimetallic NCs have two common types (Scheme 1): surface decoration and uniform alloy. The surface decoration can be achieved by direct electrodeposition of target atoms at controlled 
coverage from the solution containing dilute foreign metal ions, or through under potential depositing monolayer (ML) or sub-ML $\mathrm{Cu}$ on surface firstly, and then displacing $\mathrm{Cu}$ with target metals. The coverage of foreign atoms can be evaluated by the suppression in the hydrogen adsorption/desorption. It has been demonstrated that the catalytic activity of THH Pt NCs decorated by $\mathrm{Bi}, \mathrm{Au}$ or Ru was significantly enhanced towards formic acid or methanol electrooxidation. ${ }^{37-39}$

In the case of formic acid electrooxidation on $\mathrm{Pt}$, a dual path mechanism is widely accepted that the reactive intermediates are suggested to be adsorbed $\mathrm{COOH}$ or HCOO (direct pathway), while the poisoning intermediate is adsorbed $\mathrm{CO}$ (indirect pathway). ${ }^{28,29}$ THH Pt NCs suffer from severe CO poisoning at low potentials due to a high binding energy in comparison with those on low energy facets. This is confirmed by the fact that the rather smaller peak current density in the positive going scan than that in the negative going scan in the voltammetric test. ${ }^{37}$

Irreversible adsorption of $\mathrm{Bi}$ atoms has been introduced to modify the surface of $\{730\}$-bounded THH Pt NCs for inhibiting the poison formation, and the oxidation current increases significantly (Figure 4a). ${ }^{37}$ Note that at a very high Bi coverage up to $0.9 \mathrm{ML}$, the highest peak current $\left(25.8 \mathrm{~mA} \mathrm{~cm}^{-2}\right)$ is obtained which is 21 times larger than that on bare THH Pt NCs. Meantime, the onset potential is negatively shifted from $0.04 \mathrm{~V}$ to $-0.18 \mathrm{~V}$ (vs SCE). The reduced hysteresis between the positive and negative going scans strongly indicates the disappearance of $\mathrm{CO}$ poisoning formation at such a high Bi coverage (Figure 4b). Also, the stability is improved that, after $60 \mathrm{~s}$, the current density on THH Pt NCs quickly decays to $0.003 \mathrm{~mA} \mathrm{~cm}^{-2}$, however with the $0.9 \mathrm{ML} \mathrm{Bi}$ coverage, the current density was recorded to be 2.78 $\mathrm{mA} \mathrm{cm}$ (Figure 4c). It is generally accepted that the formation of $\mathrm{CO}$ requires an ensemble of Pt surface atoms, ${ }^{32-33,40}$ and the Bi adatoms decrease the amount of available ensembles that suppresses the poisoning species formation (so-called third body effect). ${ }^{32}$ Additionally, the larger current, particularly at a low Bi coverage, indicates that $\mathrm{Bi}$ adatoms may also contribute to an electronic structure enhancement for formic acid oxidation. ${ }^{34}$ Likewise, Au adatoms on THH Pt NCs also have a promoting role in formic acid electrooxidation with increased activity and stability. ${ }^{38}$ 
Different from the Bi decoration, the activity decreases once the Au coverage is above $0.72 \mathrm{ML}$. The promotional role of Au atoms is mainly attributed to third body effect that suppresses the indirect pathway through poisoning CO adsorbates. ${ }^{28,29}$ Thus, although the decoration of $\mathrm{Au}$ atoms would block active Pt sites for reactions, it can promote the $\mathrm{CO}_{2}$ formation.

PtRu catalysts are the most common and efficient anode materials in direct methanol fuel cells because of the bi-functional mechanism. ${ }^{30}$ The surface $\mathrm{Ru}$ atoms as illustrated in Figure 4d, were suggested to provide adsorbed oxygen-containing species that facilitates oxidation of intermediates produced from methanol decomposition to $\mathrm{CO}$ adsorbates at low potentials. The significant enhancement from $\mathrm{Ru}$ adatoms was experimentally found to be sensitive towards surface structure by using Pt single crystal planes with the activity order of $(111)>(110)>(100) .{ }^{41}$ As for $\mathrm{CO}$ electrooxidation, the onset potential is $0.41 \mathrm{~V}$ (vs SCE) on the THH Pt NCs and the peak potential is at $0.53 \mathrm{~V}$ (vs SCE). ${ }^{39}$ When the Ru coverage increases, both the onset and peak potentials are negatively shifted. As for methanol electrooxidation, the onset potential is negatively shifted by $0.10 \mathrm{~V}$, and the current at low potentials is dramatically enhanced in the presence of decorated $\mathrm{Ru}$ atoms (Figure 4e). The transient current curves recorded at $0.25 \mathrm{~V}$ (vs SCE) also show better stability for methanol oxidation (Figure 4f). An interesting observation is that the improvement of Ru modification on THH Pt NCs is more remarkable than that on Pt black. The reason may be that Ru adatoms prefer to block the step sites. Since the step sites on normal Pt NCs are low, once they are blocked by $\mathrm{Ru}$, the methanol dehydrogenation process would be limited. While on the THH Pt NCs with a high density of step sites, even though in the presence of Ru adatoms, there are still a portion of step sites that can be utilized for facilitating the methanol dehydrogenation.

Alloying is another strategy by adding foreign atoms into the crystal lattice. In comparison with the surface decoration, the synthesis of alloy NCs with tunable shape and composition is more difficult due to the difference in intrinsic standard reduction potential and lattice constant between the alloy metals. The alloyed elements can modify the electronic structure for tuning the binding energy of adsorbed 
intermediates, or provide bifunctional mechanisms. It is thus anticipated that high-index faceted bimetallic alloy NCs may have high catalytic activity owing to the synergy effect from steric structure and electronic structure.

THH Pd ${ }_{9} \mathrm{Pt}$ alloy NCs with $\left\{\begin{array}{lll}10 & 3 & 0\end{array}\right\}$ facets have been directly electrodeposited on glassy carbon electrode in $\mathrm{PdCl}_{2}$ and $\mathrm{K}_{2} \mathrm{PtCl}_{6}$ mixed solution by the SWP method. ${ }^{42}$ Clearly, the elemental distribution of Pd and Pt is very uniform with a slight enrichment of Pt at edge sites (Figure 5a). For the alloy THH PdPt NCs towards formic acid electrooxidation, the peak current density increases with increasing Pt content, and reaches a maximum $\left(70 \mathrm{~mA} \cdot \mathrm{cm}^{-2}\right)$ at Pt content of $10 \%$. The catalytic activity is 3.1 times higher than that on pure THH Pd NCs $\left(22.4 \mathrm{~mA} \cdot \mathrm{cm}^{-2}\right)$, and also 6.2 times higher than that on commercial Pd black $\left(11.3 \mathrm{~mA} \cdot \mathrm{cm}^{-2}\right)$ (Figure 5b). Additionally, the peak potential for formic acid oxidation on THH PdPt alloy NCs is shifted negatively in comparison with Pd black, leading to a large catalytic activity enhancement at low potentials. The current densities at $0 \mathrm{~V}$ (vs. SCE) are 36.8, 3.25, and $1.64 \mathrm{~mA} \mathrm{~cm}^{-2}$ on THH Pd${ }_{9} \mathrm{Pt} \mathrm{NCs}$, THH Pd NCs and commercial Pd black, respectively.

$\mathrm{Rh}$ is an effective metal to split the $\mathrm{C}-\mathrm{C}$ bond in ethanol electrooxidation. ${ }^{43,44}$ Tian et al. further synthesized PtRh alloy THH NCs with $\{830\}$ facets and TPH NCs with $\{311\}$ facets by using the SWP method in mixed solution of $\mathrm{K}_{2} \mathrm{PtCl}_{6}$ and $\mathrm{RhCl}_{3}{ }^{45}$ With a small amount of $\mathrm{Rh}(4 \%)$ being introduced and uniformly distributed in both THH and TPH Pt NCs, the high-index faceted PtRh NCs are much more effective to break the $\mathrm{C}-\mathrm{C}$ bond of ethanol, yielding much more $\mathrm{CO}_{2}$ than that of the pure Pt catalysts. The activity increases in the order of PtRh TPH $\left(4.19 \mathrm{~mA} \cdot \mathrm{cm}^{-2}\right)>$ PtRh THH $\left(3.27 \mathrm{~mA} \cdot \mathrm{cm}^{-2}\right)>$ Pt TPH $\left(2.90 \mathrm{~mA} \cdot \mathrm{cm}^{-2}\right)>$ Pt THH $\left(2.70 \mathrm{~mA} \cdot \mathrm{cm}^{-2}\right)>$ $\mathrm{Pt} / \mathrm{C}\left(0.66 \mathrm{~mA} \cdot \mathrm{cm}^{-2}\right)$. After 100 potential cycles during the electrochemical tests, only $5 \%$ of peak current density decayed.

Jia et al. synthesized the unique excavated rhombic dodecahedral (ERD) $\mathrm{PtCu}_{3}$ alloy NCs exposed by $\{110\}$ facets as shown in Figure 5c. ${ }^{46}$ It was observed that with the increase of n-butylamine amount, the morphologies of $\mathrm{PtCu}_{3} \mathrm{NCs}$ evolved from the octahedron, to the edge-concave octahedron and finally to the ERD structure. 
Figure 5d presents the surface structure effect on formic acid electrooxidation by comparing ERD $\mathrm{PtCu}_{3} \mathrm{NCs}$ with edge-concaved octahedral $\mathrm{PtCu}_{3} \mathrm{NCs}$ with $\{110\}$ and $\{111\}$ facets, and octahedral $\mathrm{PtCu}_{3} \mathrm{NCs}$ with $\{111\}$ facets. Although such ERD $\mathrm{PtCu}_{3} \mathrm{NCs}$ are relatively large (around $50 \mathrm{~nm}$ ), a very large surface area $\left(77 \mathrm{~m}^{2} \mathrm{~g}^{-1}\right)$ due to ultrathin nanosheet structure still makes they exhibit excellent mass activity towards formic acid electrooxidation. The measured mass current density on the ERD $\mathrm{PtCu}_{3}$ alloy NCs is $815 \mathrm{~mA} \mathrm{mg}^{-1}$ at $0.65 \mathrm{~V}$ (vs SCE) that is about 2.6 times larger than that on the commercial Pt black $\left(310 \mathrm{~mA} \mathrm{mg}^{-1}\right)$. Xu et al. reported a one-pot fabrication strategy to synthesize concave cubic and $\mathrm{HOH}$ PtNi alloy NCs by tuning the glycine concentration. ${ }^{46}$ Concave cubic PtNi NCs were formed at a low glycine concentration by self-assembly, but $\mathrm{HOH}$ PtNi NCs could evolve at a high glycine concentration. The facets on concave cubic PtNi NCs include $\{610\},\{510\},\{410\}$ and $\{720\}$, while on $\mathrm{HOH}$ PtNi NCs are $\{521\}$ facets. The oxidation current densities on $\mathrm{HOH}$ and concave cubic PtNi NCs are 3.6 and 3.9 times higher than that on $\mathrm{Pt} / \mathrm{C}$ catalysts towards methanol electrooxidation; and 2.2 and 1.9 times higher than that of $\mathrm{Pt} / \mathrm{C}$ for formic acid electrooxidation, respectively. For oxygen reduction reaction, the area specific activities at $0.90 \mathrm{~V}$ (vs RHE) of the $\mathrm{HOH}\left(1.08 \mathrm{~mA} \mathrm{~cm}^{-2}\right)$, and concave cubic PtNi NCs $\left(0.44 \mathrm{~mA} \mathrm{~cm}^{-2}\right)$ are 4.9 and 2 times higher than that of $\mathrm{Pt} / \mathrm{C}$ catalysts $\left(0.22 \mathrm{~mA} \mathrm{~cm}^{-2}\right)$, respectively.

The studies of nanocrystal catalysts of high-energy surface have already opened a new and exciting avenue to design exceptional properties for electrocatalysis. The NCs enclosed with high-energy surfaces and well-defined atomic arrangement could provide a new model catalyst for studying of structure-reactivity functionality at the nanoscale, which requires to precisely and continuously control the surface structure of NCs. The size control of the high energy surface NCs, especially those of sub-10 $\mathrm{nm}$ in terms of enhancing the mass activity in catalysis is still an important issue for bimetallic or trimetallic NCs. For bimetallic systems, systematically tuning the surface structure of catalysts to change the properties can become more effective practically. In addition, the exploration of metal oxide-supported NCs with high surface energy, as well as their application in heterogeneous catalysis is also 
promising. However, the exceptional properties of NCs with high-energy surfaces have been mostly demonstrated in the laboratory, it is vital to explore synthesis technologies for scaling-up to large batch production/manufacture.

\section{Biographical Information}

Tian Sheng received his B.S. degree from East China University of Science and Technology in 2011, and Ph.D. degree from Queen's University Belfast in 2014. His research is to simulate electrocatalytic reactions using density functional theory.

Na Tian received her $\mathrm{PhD}$ degree in 2007 from Xiamen University. She is an associate professor at Xiamen University and her research interests include electrocatalysis and nanomaterials, especially electrochemical synthesis of metal nanocatalysts with high-index facets.

Zhou-You Zhou received his $\mathrm{PhD}$ degree in 2004 from Xiamen University. He is professor at Xiamen University and his research interests include electrocatalysis and nanomaterials, especially non-precious metal catalysts for fuel cells.

Wen-Feng Lin received his $\mathrm{PhD}$ in 1991 from Xiamen University. He is a professor in Chemical Engineering at Loughborough University in England, a Fellow of the Royal Society of Chemistry. His research interests include energy materials, fuel cells, electro-catalysis, interface electrochemistry and electrochemical engineering.

Shi-Gang Sun received Doctorat d'Etat in 1986 from Université Pierre et Marie Curie (Paris VI), France, and is currently a professor at Xiamen University. He is a member of Chinese Academy of Sciences, a Fellow of the Royal Society of Chemistry, U.K., and a Fellow of the International Society of Electrochemistry. His research interests include electrocatalysis, electrochemical surface sciences, spectroelectrochemistry, and chemical power sources.

\section{Acknowledgement}

This work is supported by NSFC (21621091, 21573183, 21229301 and 21361140374). 


\section{References}

(1) Zhou, Z. Y.; Tian, N.; Li, J. T.; Broadwell, I.; Sun, S. G. Nanomaterials of High Surface Energy with Exceptional Properties in Catalysis and Energy Storage. Chem. Soc. Rev. 2011, 40, 4167-4185.

(2) Lebedeva, N. P.; Rodes, A.; Feliu, J. M.; Koper, M. T. M.; van Santen, R. A. Role of Crystalline Defects in Electrocatalysis: CO Adsorption and Oxidation on Stepped Platinum Electrodes as Studied by in situ Infrared Spectroscopy. J. Phys. Chem. B 2002, 106, 9863-9872.

(3) Chen, Q. S.; Berna, A.; Climent, V.; Sun, S. G.; Feliu, J. M. Specific Reactivity of Step Sites towards CO Adsorption and Oxidation on Platinum Single Crystals Vicinal to Pt(111). Phys. Chem. Chem. Phys. 2010, 12, 11407-11416.

(4) Bernasek, S. L.; Somorjai, G. A. Small Molecule Reactions on Stepped Single Crystal Platinum Surfaces. Surf. Sci. 1975, 48, 204-213.

(5) Tian, N.; Zhou, Z. Y.; Sun, S. G. Platinum Metal Catalysts of High-Index Surfaces: From Single-Crystal Planes to Electrochemically Shape-Controlled Nanoparticles. $J$. Phys. Chem. C 2008, 112, 19801-19817.

(6) Sheng, T.; Xu, Y. F.; Jiang, Y. X.; Huang, L.; Tian, N.; Z. Y. Zhou, Z. Y.; Broadwell, I., Sun S. G. Structure Design and Performance Tuning of Nanomaterials for Electrochemical Energy Conversion and Storage. Acc. Chem. Res. 2016, 49, 2569-2577.

(7) Zhang, H.; Jin, M.; Xiong, Y.; Lim, B.; Xia, Y. Shape-Controlled Synthesis of Pd Nanocrystals and Their Catalytic Applications. Acc. Chem. Res. 2013, 46, 1783-1794.

(8) Porter, N. S.; Wu, H.; Quan, Z.; Fang, J. Shape-Control and Electrocatalytic Activity-Enhancement of Pt-Based Bimetallic Nanocrystals. Acc. Chem. Res. 2013, $46,1867-1877$.

(9) Chen, Q.; Jia, Y.; Xie, S.; Xie, Z. Well-Faceted Noble-Metal Nanocrystals with Nonconvex Polyhedral Shapes. Chem. Soc. Rev. 2016, 45, 3207-3220.

(10) Visintin, A.; Canullo, J. C.; Triaca, W. E.; Arvia, A. J. Changes in Real Surface-Area Crystallographic Orientation and Morphology of Platinum-Electrodes Caused by Periodic Potential Treatments-Phenomenological Approach. J. Electroanal. 
Chem. 1988, 239, 67-89.

(11) Tian, N.; Zhou, Z. Y.; Sun, S. G.; Ding, Y.; Wang, Z. L. Synthesis of

Tetrahexahedral Platinum Nanocrystals with High-Index Facets and High Electro-oxidation Activity. Science 2007, 316, 732-735.

(12) Tian, N.; Zhou, Z. Y.; Yu, N. F.; Wang, L. Y.; Sun, S. G. Direct electrodeposition of tetrahexahedral Pd nanocrystals with high-index facets and high catalytic activity for ethanol electrooxidation, J. Am. Chem. Soc. 132, 7580-7581.

(13) Yu, N. F.; Tian, N.; Zhou, Z. Y.; Huang, L.; Xiao, J.; Wen, Y. H.; Sun, S. G. Electrochemical Synthesis of Tetrahexahedral Rhodium Nanocrystals with Extraordinarily High Surface Energy and High Electrocatalytic Activity, Angew. Chem. Int. Ed. 2014, 53, 5097-5101

(14) Xiao, J.; Liu, S.; Tian, N.; Zhou, Z. Y.; Liu, H. X.; Xu B. B; Sun, S. G. Synthesis of Convex Hexoctahedral Pt Micro/Nanocrystals with High-Index Facets and Electrochemistry-Mediated Shape Evolution. J. Am. Chem. Soc. 2013, 135, 18754-18757.

(15) Zhou, Z. Y.; Shang, S. J.; Tian, N.; Wu, B. H.; Zheng, N. F.; Xu, B. B.; Chen, C.; Wang, H. H.; Xiang, D. M.; Sun, S. G. Shape Transformation from Pt Nanocubes to Tetrahexahedra with Size near $10 \mathrm{~nm}$. Electrochem. Commun. 2012, 22, 61-64.

(16) Liu, S.; Tian, N.; Xie, A. Y.; Du, J. H.; Xiao, J.; Liu, L.; Sun, H. Y.; Cheng, Z. Y.; Zhou, Z. Y.; Sun, S. G. Electrochemically Seed-Mediated Synthesis of Sub-10 nm Tetrahexahedral Pt Nanocrystals Supported on Graphene with Improved Catalytic Performance. J. Am. Chem. Soc. 2016, 138, 5753-5756.

(17) Zhou, Z. Y.; Huang, Z. Z.; Chen, D. J.; Wang, Q.; Tian, N.; Sun, S. G. High-Index Faceted Platinum Nanocrystals Supported on Carbon Black as Highly Efficient Catalysts for Ethanol Electrooxidation. Angew. Chem. Int. Ed. 2010, 49, 411-414.

(18) Li, Y.; Jiang, Y.; Chen, M.; Liao, H.; Huang, R.; Zhou, Z.; Tian, N.; Chen, S.; Sun, S. G. Electrochemically Shape-Controlled Synthesis of Trapezohedral Platinum Nanocrystals with High Electrocatalytic Activity. Chem. Commun. 2012, 48, 9531-9533. 
(19) Zhou, Z. Y.; Tian, N.; Huang, Z. Z.; Chen, D. J.; Sun, S. G. Nanoparticle catalysts with high energy surfaces and enhanced activity synthesized by electrochemical method, Faraday Discuss., 2008, 140, 81-92.

(20) Wei, L.; Zhou, Z. Y.; Chen, S. P.; Xu, C. D.; Su, D.; Schuster, M. E.; Sun, S. G. Electrochemically Shape-controlled Synthesis in Deep Eutectic Solvents: Triambic Icosahedral Platinum Nanocrystals with High-Index Facets and Their Enhanced Catalytic Activity. Chem. Commun. 2013, 49, 11152-11154.

(21) Wei, L.; Fan, Y. J.; Tian, N.; Zhou, Z. Y.; Zhao, X. Q.; Mao, B. W.; Sun, S. G. Electrochemically Shape-Controlled Synthesis in Deep Eutectic Solvents-A New Route to Prepare Pt Nanocrystals Enclosed by High-Index Facets with High Catalytic Activity. J. Phys. Chem. C 2012, 116, 2040-2044.

(22) Huang, X.; Zhao, Z.; Fan, J.; Tan, Y.; Zheng, N. Amine-Assisted Synthesis of Concave Polyhedral Platinum Nanocrystals Having $\{411\}$ High-Index Facets. J. Am. Chem. Soc. 2011, 133, 4718-4721.

(23) Yu, T.; Kim, D. Y.; Zhang, H.; Xia, Y. Platinum Concave Nanocubes with High-Index Facets and Their Enhanced Activity for Oxygen Reduction Reaction. Angew. Chem. Int. Ed. 2011, 50, 2773-2777.

(24) Zhang, L.; Chen, D.; Jiang, Z.; Zhang, J.; Xie, S.; Kuang, Q.; Xie, Z.; Tian, Z. Facile Synthesis and enhanced electocatalytic activities of Pt nanocrystals with $\{\mathrm{hkk}\}$ high-index surfaces. Nano Res. 2012, 5, 181-189.

(25) Lai, S. C. S.; Koper, M. T. M. The Influence of Surface Structure on Selectivity in the Ethanol Electro-oxidation Reaction on Platinum. J. Phys. Chem. Lett. 2010, 1, 1122-1125.

(26) Sheng, T.; Lin, W. F.; Sun S. G. Elucidation of the Surface Structure-Selectivity Relationship in Ethanol Electro-Oxidation over Platinum by Density Functional Theory. Phys. Chem. Chem. Phys. 2016, 18, 15501-15504.

(27) Ye, J. Y.; Jiang, Y. X.; Sheng, T.; Sun, S. G. In-situ FTIR Spectroscopic Studies of Electrocatalytic Reactions and Processes, Nano Energ. 2016, 29, 414-427.

(28) Sun, S. G.; Clavilier, J.; Bewick, A. The Mechanism of Electrocatalytic Oxidation of Formic-Acid on $\operatorname{Pt}(100)$ and $\operatorname{Pt}(111)$ in Sulfuric-Acid Solution-an 
EMIRS Study. J. Electroanal. Chem. 1988, 240, 147-159.

(29) Cuesta, A.; Cabello, G.; Osawa, M.; Gutiérrez, C. Mechanism of the Electro-Catalytic Oxidation of Formic Acid on Metals. ACS Catal. 2012, 2, 728-738.

(30) Watanabe, M.; Motoo, S. Electrocatalysis by Ad-Atoms. 2. Enhancement of Oxidation of Methanol on Platinum by Ruthenium Ad-Atoms. J. Electroanal Chem. Interfacial Electrochem. 1975, 60, 267-273.

(31) Herrero, E.; Feliu, J. M.; Aldaz, A. Posion Formation Reaction from Formic-Acid on Pt(100) Electrodes Modified by Irreversibly Adsorbed Bismuth and Antimony. $J$. Electroanal. Chem. 1994, 368, 101-108.

(32) Leiva, E.; Iwasita, T.; Herrero, E.; Feliu, J. M. Effect of Adatoms in the Electocatalysis of HCOOH Oxidation. A Theoretical Study. Langmuir 1997, 13, 6287-6293.

(33) Neurock, M.; Janik, M.; Wieckowski, A. A First Principles Comparison of the Mechanism and Site Requirements for the Electrocatalytic Oxidation of Methanol and Formic Acid over Pt. Faraday Discuss. 2008, 140, 363-378.

(34) Herrero, E.; Fernandez-Vega, A.; Feliu, J. M.; Aldaz, A. Poison Formation Reaction from Formic-Acid and Methanol on $\mathrm{Pt}(111)$ Electrodes Modified by Irreversibly Adsorbed Bi and As. J. Electroanal. Chem. 1993, 350, 73-88.

(35) Obradović, M. D.; Tripković, A. V.; Gojković, S. L. The Origin of High Activity of Pt-Au Surfaces in the Formic Acid Oxidation. Electrochim. Acta 2009, 55, 204-209.

(36) J. K. Norskov, F. Abild-Pedersen, F. Studt, T. Bligaard, Density functional theory in surface chemistry and catalysis, Proc. Natl. Acad. Sci. U.S.A., 2011, 108, 937-943

(37) Chen, Q. S.; Zhou, Z. Y.; Vidal-Iglesias, F. J.; Solla-Gullón, J.; Feliu, J. M.; Sun, S. G. Significantly Enhancing Catalytic Activity of Tetrahexahedral Pt Nanocrystals by Bi Adatom Decoration. J. Am. Chem. Soc. 2011, 133, 12930-12933.

(38) Liu, H. X.; Tian, N.; Brandon, M. P.; Pei, J.; Huangfu, Z. C.; Zhan, C.; Zhou, Z. Y.; Hardacre, C.; Lin, W. F.; Sun, S. G. Enhancing the Activity and Tuning the Mechanism of Formic Acid Oxidation at Tetrahexahedral Pt Nanocrystals by $\mathrm{Au}$ Decoration. Phys. Chem. Chem. Phys. 2012, 14, 16415-16423. 
(39) Liu, H. X.; Tian, N.; Brandon, M. P.; Zhou, Z. Y.; Lin, J. L.; Hardacre, C.; Lin, W. F.; Sun, S. G. Tetrahexahedral Pt Nanocrystal Catalysts Decorated with Ru Adatoms and Their Enhanced Activity in Methanol Electrooxidation. ACS Catal. 2012, 2, 708-715.

(40) Cuesta, A.; Escudero, M.; Lanova, B.; Baltruschat, H. Cyclic Voltammetry, FTIRS, and DEMS Study of the Electrooxidation of Carbon Monooxide, Formic Acid, and Methanol on Cyanide-Modified Pt(111) Electrodes, Langmuir 2009, 25, 6500-6507.

(41) Chrzanowski, W.; Wieckowski, A. Surface Structure Effects in Platinum/Ruthenium Methanol Oxidation Electrocatalysis. Langmuir 1998, 14, 1967-1970.

(42) Deng, Y. J.; Tian, N.; Zhou, Z. Y.; Huang, R.; Liu, Z. L.; Xiao, J.; Sun, S. G. Alloy Tetrahexahedral Pd-Pt Catalysts: Enhancing Significantly the Catalytic Activity by Synergy Effect of High-Index Facets and Electronic Structure. Chem. Sci. 2012, 3, 1157-1161.

(43) Kowal, A.; Li, M.; Shao, M.; Sasaki, K.; Vukmirovic, M. B.; Zhang, J.; Marinkovic, N. S.; Liu, P.; Frenkel, A. I.; Adzic, R. R. Ternary Pt/Rh/SnO $\mathrm{Sn}_{2}$ Electrocatalysts for Oxidizing Ethanol to $\mathrm{CO}_{2}$. Nat. Mater. 2009, 8, 325-330.

(44) Sheng, T.; Lin, W. F.; Hardacre, C.; Hu, P. Significance of beta-Dehydrogenation in Ethanol Electro-Oxidation on Platinum Doped with Ru, Rh, Pd, Os and Ir. Phys. Chem. Chem. Phys. 2014, 16, 13248-13254.

(45) Tian, N.; Xiao, J.; Zhou, Z. Y.; Liu, H. X.; Deng, Y. J.; Huang, L.; Xu, B. B.; Sun, S. G. Pt-group Bimetallic Nanocrystals with High-Index Facets as High Performance Electrocatalysts. Faraday Discuss. 2013, 162, 77-89.

(46) Jia, Y.; Jiang, Y; Zhang, J; Zhang, L.; Chen, Q.; Xie, Z.; Zheng, L. Unique Excavated Rhombic Dodecahedral $\mathrm{PtCu}_{3}$ Alloy Nanocrystals Constructed with Ultrathin Nanosheets of High-Energy $\{110\}$ Facets. J. Am. Chem. Soc. 2014, 136, 3748-3751.

(47) Xu, X. L.; Zhang, X.; Sun, H.; Yang, Y.; Dai, X. P.; Gao, J. S.; Li, X. Y.; Zhang, P. F.; Wang, H. H.; Yu, N. F. et al. Synthesis of Pt-Ni Alloy Nanocrystals with 
High-Index Facets and Enhanced Electrocatalytic Properties. Angew. Chem. Int. Ed. 2014, 53, 12522-12527.

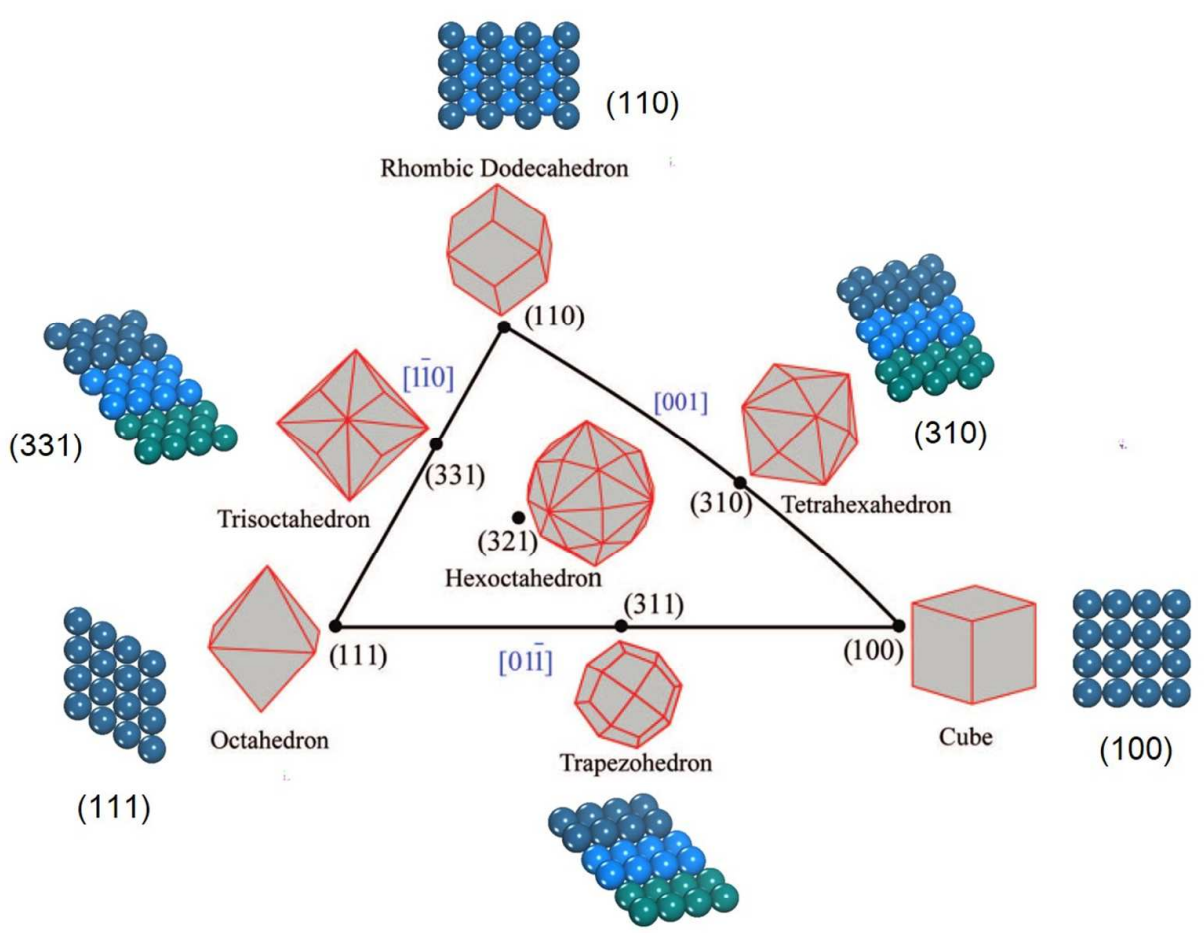

(311)

Figure 1. Unit stereographic triangle of fcc metal polyhedral NCs bounded by different crystal plane ${ }^{5}$ and models of surface atomic arrangement. Copyright 2008, American Chemical Society. 
(a)
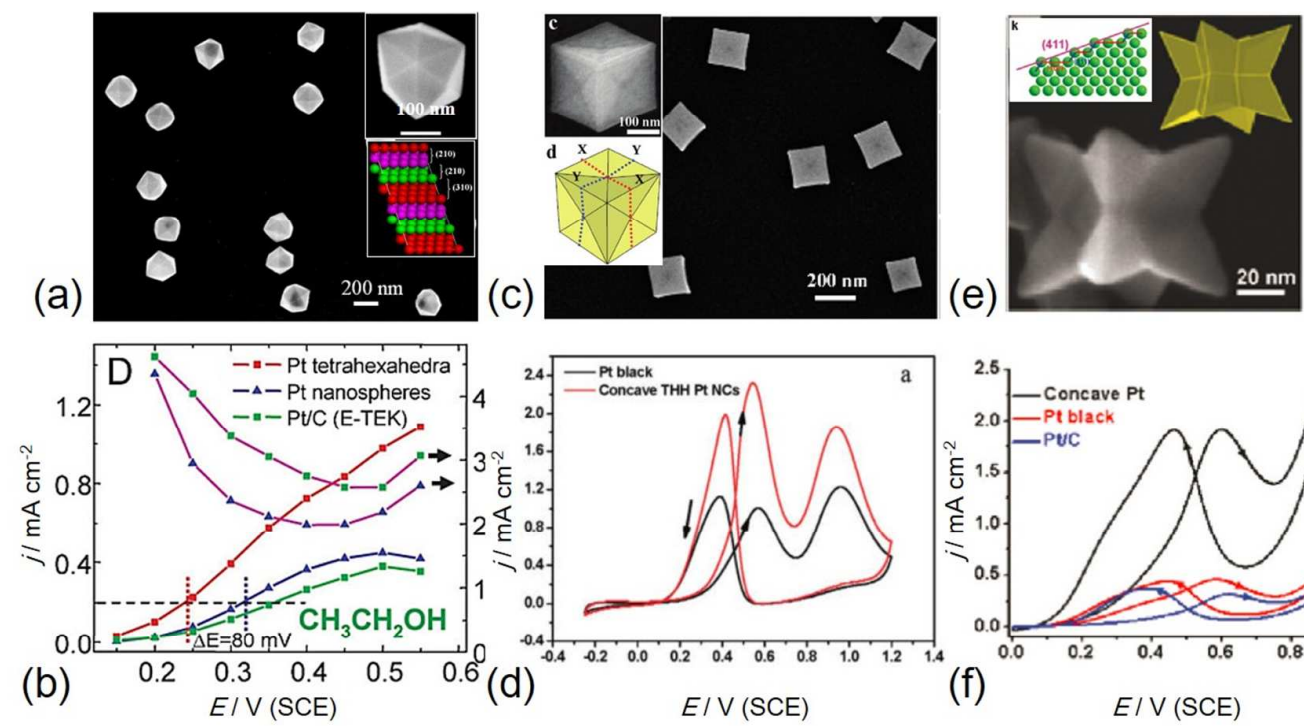

(d)

$E / V(S C E)$

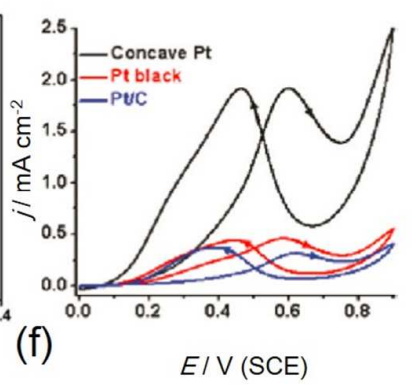

Figure 2. (a) SEM images of Pt THH NCs with the corresponding high-magnification SEM images and atomic models. ${ }^{11}$ (b) Steady-state current as a function of electrode potential for ethanol electrooxidation in $0.1 \mathrm{M}$ ethanol $+0.1 \mathrm{M} \mathrm{HClO}_{4}{ }^{11}$ (c) SEM images of concave Pt THH NCs with the corresponding high-magnification SEM images and model images of a concave THH Pt NC. ${ }^{21}$ (d) Cyclic voltammograms of concave Pt NCs in $0.1 \mathrm{M}$ ethanol $+0.1 \mathrm{M} \mathrm{HClO}_{4}$ (scan rate: $50 \mathrm{mV} \mathrm{s}^{-1}$ ). ${ }^{21}$ (e) High-magnification SEM image of concave Pt NCs with the inset figures showing the atomic model. $^{22}$ (f) Cyclic voltammograms of concave Pt NCs in $0.1 \mathrm{M}$ ethanol +0.1 $\mathrm{M} \mathrm{HClO}_{4}$ (scan rate: $50 \mathrm{mV} \mathrm{s}^{-1}$ ). ${ }^{22}$ Copyright 2007, the American Association for the Advancement of Science. Copyright 2011, 2012, American Chemical Society. 
(a)
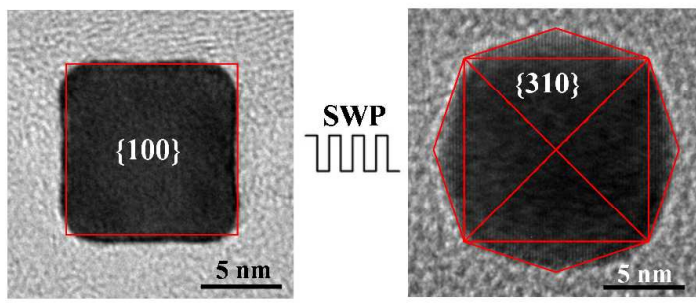

(d)

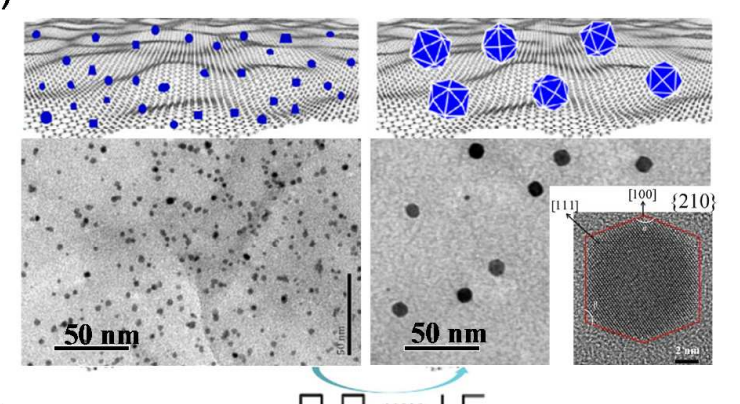

(c)
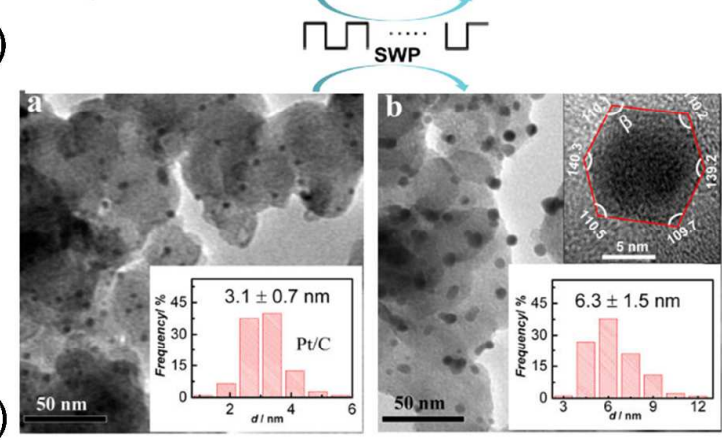
Elsevier; Copyright 2016, American Chemical Society.
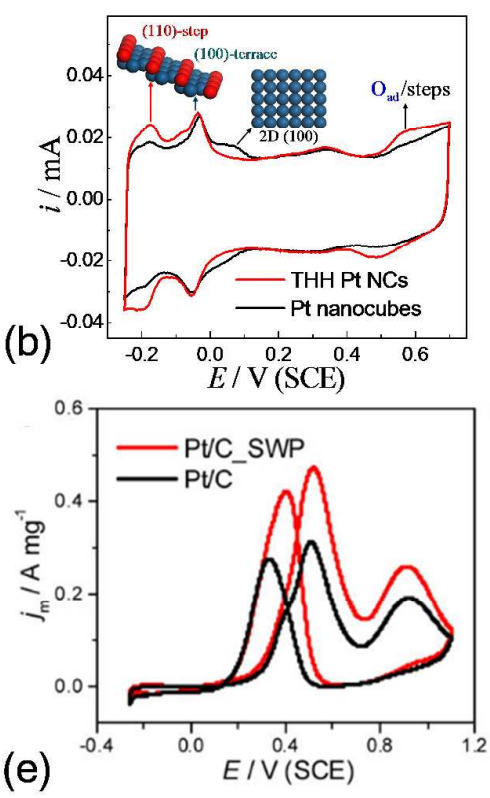

(e)

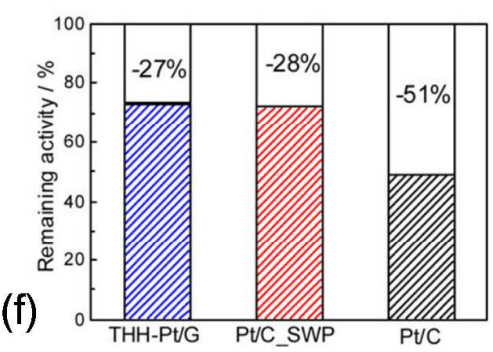

Figure 3. (a) Shape transformation from $10 \mathrm{~nm}$-sized Pt nanocubes into $13 \mathrm{~nm}$-sized THH Pt NCs by the SWP treatment in $0.1 \mathrm{M} \mathrm{H}_{2} \mathrm{SO}_{4} \cdot{ }^{15}$ (b) Cyclic voltammograms of Pt nanocubes and THH Pt NCs in THH Pt NCs in $0.1 \mathrm{M} \mathrm{H}_{2} \mathrm{SO}_{4}$ (scan rate: $50 \mathrm{mV} \mathrm{s}^{-1}$ ). ${ }^{15}$ (c) Illustration and TEM images of sub-10 nm THH Pt NCs synthesized via an electrochemically seed-mediated method. ${ }^{16}$ (d) TEM images and size histograms of commercial $\mathrm{Pt} / \mathrm{C}$ before and after electrochemical SWP treatment in $10 \mu \mathrm{M} \mathrm{H} \mathrm{H}_{2} \mathrm{PtCl}_{6}+0.1 \mathrm{M} \mathrm{H}_{2} \mathrm{SO}_{4} \cdot{ }^{16}$ (e) Cyclic voltammograms of commercial $\mathrm{Pt} / \mathrm{C}$ catalysts before and after SWP treatment for ethanol oxidation in $0.1 \mathrm{M}$ ethanol $+0.1 \mathrm{M} \mathrm{HClO}_{4}$ (scan rate: $\left.10 \mathrm{mV} \mathrm{s}^{-1}\right)^{16}$ (f) Comparison of the remaining activity of THH-Pt/G, Pt/C_SWP, and Pt/C for ethanol oxidation after 1000 potential cycles between -0.26 and $1.10 \mathrm{~V}$ (vs SCE) (scan rate: $100 \mathrm{mV} \mathrm{s}^{-1}$ ). ${ }^{16}$ Copyright 2012, 
(d)

(b)
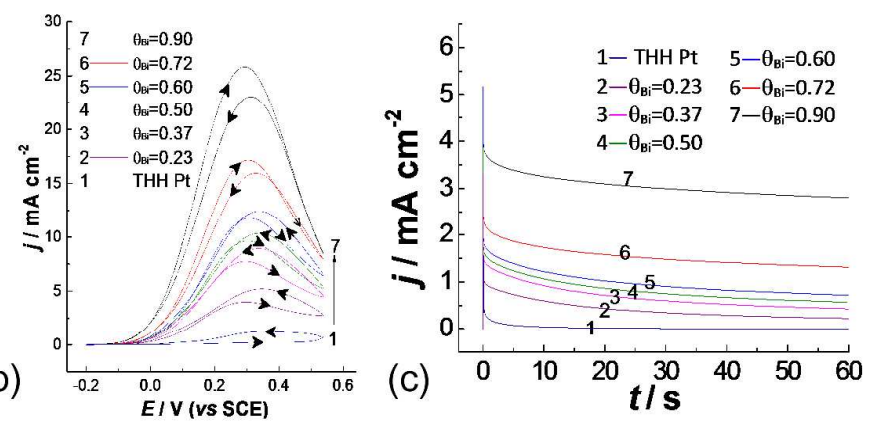

(a)
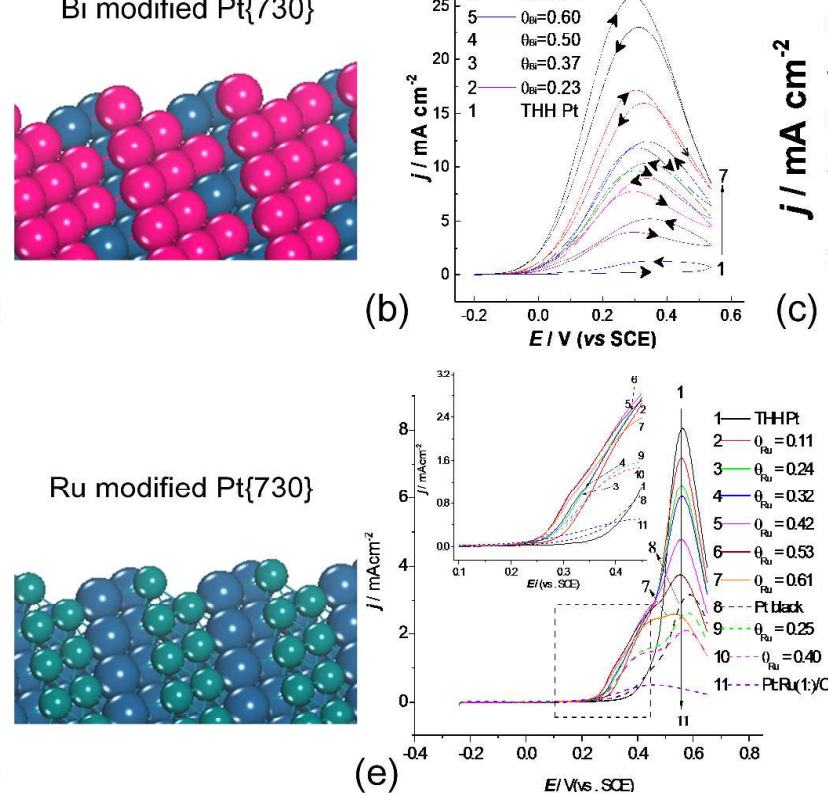

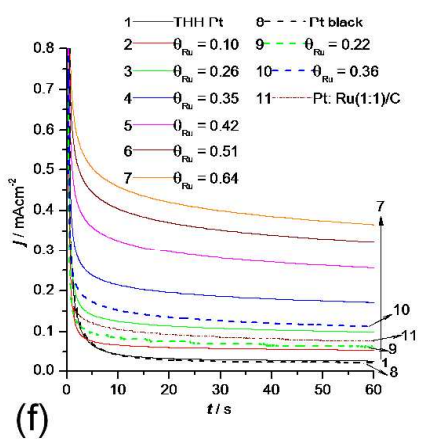

Figure 4. (a) Model of Bi modified Pt $\{730\}$ surface. (b) Cyclic voltammograms of Pt THH NCs with different Bi coverages in $0.25 \mathrm{M}$ formic acid $+0.5 \mathrm{M} \mathrm{H}_{2} \mathrm{SO}_{4}$ (scan rate: $\left.20 \mathrm{mV} \mathrm{s}^{-1}\right){ }^{37}$ (c) Comparisons of current transients recorded at $0.04 \mathrm{~V}$ (vs SCE) for formic acid oxidation on Bi modified THH Pt NCs with varying Bi coverage. ${ }^{37}$ (d) Model of $\mathrm{Ru}$ modified $\mathrm{Pt}\{730\}$ surface. (e) Positive segments of cyclic voltammograms of Pt THH NCs with different Ru coverages in $1.0 \mathrm{M}$ methanol +0.1 $\mathrm{M} \mathrm{HClO}_{4}$ (scan rate: $50 \mathrm{mV} \mathrm{s}^{-1}$ ). ${ }^{39}$ (f) Comparison of current transients recorded at $0.25 \mathrm{~V}$ (vs SCE) for methanol oxidation on Ru modified THH Pt NCs with varying Ru coverage. ${ }^{39}$

Copyright 2011, 2012, American Chemical Society. 


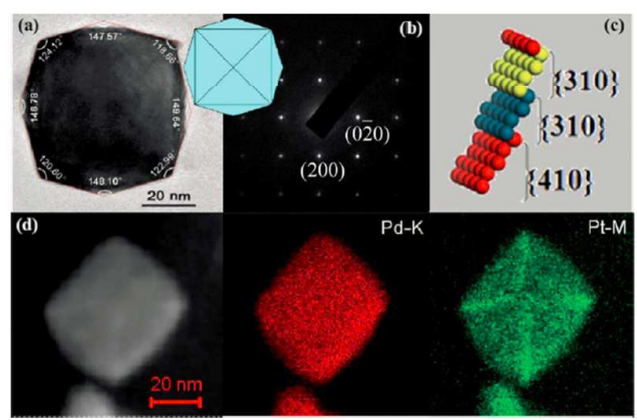

(a)
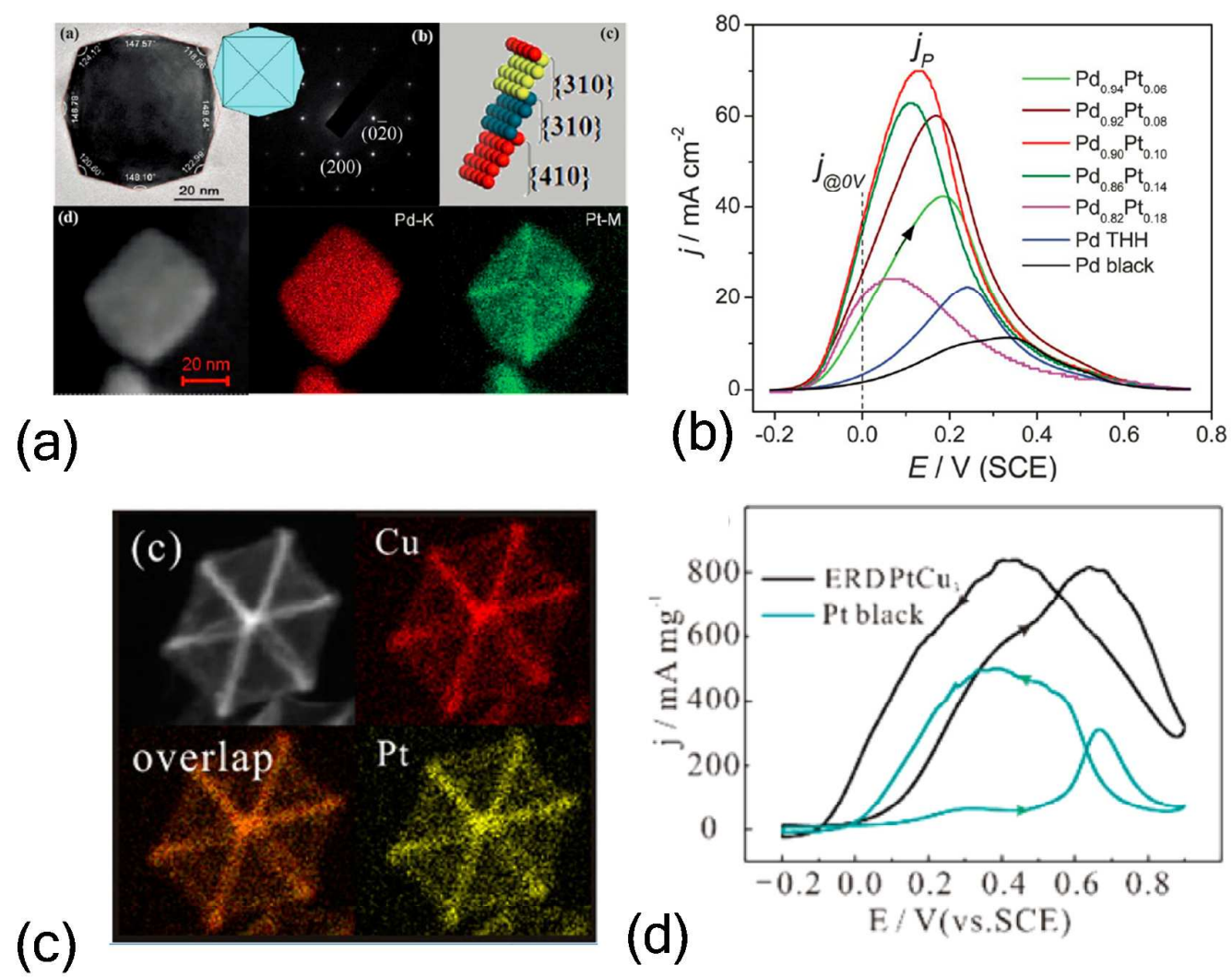

Figure 5. (a) TEM image and SAED pattern of a $\mathrm{THH} \mathrm{Pd}_{0.90} \mathrm{Pt}_{0.10} \mathrm{NC}$ recorded along the [001] crystal zone with the atomic model, STEM image and EDS elemental mapping of Pd and Pt in a THH $\mathrm{Pd}_{0.90} \mathrm{Pt}_{0.10} \mathrm{NC}^{42}$ (b) Current-potential curves of THH PdPt NCs with different Pt content in $0.25 \mathrm{M}$ formic acid + $0.25 \mathrm{M} \mathrm{HClO}_{4}$ (scan rate: $\left.50 \mathrm{mV} \mathrm{s}^{-1}\right) .^{42}$ (c) HAADF-STEM image and EDS maps of a single ERD PtCu 3 alloy NC. ${ }^{46}$ (d) Cyclic voltammograms of ERD $\mathrm{PtCu}_{3}$ alloy $\mathrm{NC}$ and Pt black in $0.25 \mathrm{M}$ formic acid $+0.5 \mathrm{M} \mathrm{H}_{2} \mathrm{SO}_{4}$. (Scan rate: $50 \mathrm{mV} \mathrm{s}^{-1}$ ). ${ }^{46}$ Copyright 2012, Royal Society of Chemistry, Copyright 2014, American Chemical Society. 
Scheme 1. Illustration of two strategies of bimetallic NCs with high surface energy: surface decoration and uniform alloy.

Table 1 Comparison of the specific area activity $\left(\mathrm{mA} \cdot \mathrm{cm}^{-2}\right)$ at the peak current on the NCs with high index facets for electrooxidation of ethanol and formic acid.

\begin{tabular}{|c|c|c|c|}
\hline & $\begin{array}{l}\text { Specific area activity } \\
\qquad\left(\mathrm{mA} \cdot \mathrm{cm}^{-2}\right)\end{array}$ & facets & ref \\
\hline \multicolumn{4}{|l|}{ ethanol } \\
\hline $\mathrm{Pt}$ & 3.5 & $\{730\}$ & 11 \\
\hline HIF Pt/C & 4.3 & $\{110\},\{210\}$ et al. & 17 \\
\hline $\mathrm{Pt}$ & 8.4 & $\{310\}$ & 15 \\
\hline $\mathrm{Pt}$ & 5.4 & $\{100\}$ & 15 \\
\hline PtRh & 4.2 & $\{311\}$ & 45 \\
\hline PtRh & 3.3 & $\{830\}$ & 45 \\
\hline $\mathrm{Pt}$ & 2.9 & $\{311\}$ & 45 \\
\hline $\mathrm{Pt}$ & 2.7 & $\{830\}$ & 45 \\
\hline \multicolumn{4}{|l|}{ formic acid } \\
\hline $\mathrm{PdPt}$ & 70 & $\{10,3,0\}$ & 42 \\
\hline $\mathrm{Pd}$ & 22.4 & $\{10,3,0\}$ & 42 \\
\hline PtBi & 25.8 & $\{730\}$ & 37 \\
\hline $\mathrm{PtAu}$ & 4.6 & $\{730\}$ & 38 \\
\hline $\mathrm{Pt}$ & $0.21,0.23$ & $\{730\}$ & 37,38 \\
\hline
\end{tabular}




\section{Quotes}

Pt-based electrocatalysts with high surface energy possess a high activity and stability.

The electrochemical SWP method is a universal approach for the synthesis of Pt-group metal NCs enclosed with high-index facets.

The high-index faceted bimetallic alloy NCs with synergy effect from steric and electronic structure result in excellent catalytic property.

A challenge consists in how to synthesize small-sized $(<10 \mathrm{~nm}) \mathrm{Pt}$ NCs with high surface energy and producing them in large scale for practical applications. 